metal in oxygen or air-saturated concentrated nitric acid for extended periods of time. ${ }^{50}$ The concentrated nitric acid treatment leads to etching of the platinum surface and exposing of preferred crystal faces, which facilitate the dissolution of oxygen..$^{51}$ Further, the $\mathrm{Pt}-\mathrm{O}$ alloy structure formed does not collapse when the dissolved oxygen has been removed by extended periods of strong cathodic reduction in hydrogen-saturated acid solutions. ${ }^{52}$

The highly positive anodization pretreatment potential used in the present investigation, coupled with the etching processes occurring in the concentrated nitric acid, may have given rise to the incorporation of dissolved oxygen in the gold lattice, along with the formation of a preferential crystallographic orientation, as has been found for platinum. Repeated cathodic-anodic pulsing of a polycrystalline gold electrode in aqueous acid solutions has been observed to give rise to the irreversible adsorption of oxygen (dissolved oxygen). ${ }^{53}$ Further, gold (and silver) electrodes subjected to anodic-cathodic cycling in perchlorate solutions subsequently gave pzc values which were $0.2 \mathrm{~V}$ more positive $(0.4 \mathrm{~V}$ more positive in the case of silver) than those of "non-activated" electrodes. ${ }^{54}$ In the case of silver, it is well-known that oxygen diffuses into the bulk metal.

The structure of the gold/aqueous electrolyte interface, after anodizing under potentiostatic or potentiodynamic

(50) Hoare, J. P.; Thacker, R.; Weise, C. R. J. Electroanal. Chem. $1971,30,15$.

(51) Hoare, J. P. J. Electrochem. Soc. 1978, 125, 1768.

(52) Hoare, J. P. Electrochim. Acta 1981, 26, 225. 347 .

(53) Deborin, G.; Ershler, B. V. Acta Physicochim. URSS, 1940, 13,

(54) Bockris, J. O'M.; Argade, S. D.; Gileadi, E. Electrochim. Acta $1969,14,1259$. conditions, is very complex and is greatly influenced by the previous history of the electrode, including the nature of the potential perturbation applied to it. ${ }^{29}$ Even in the case of the gold [111] single crystal, the pzc for this face in perchloric acid was found to vary substantially $(+0.200$ to $+0.288 \mathrm{~V}$ ), for the same sample, according to the potential-time perturbation applied before recording the capacitance-potential profile. ${ }^{55}$ Similarly, for the gold [100] crystal face, a scatter in the pzc values obtained has been attributed to the fact that a small change in the scan limits of the applied potential perturbation can easily cause a shift of $0.050 \mathrm{~V}$ to the value of the pzc. ${ }^{56}$

In conclusion, the rather high values for the measured pzc for polycrystalline gold in $0.1 \mathrm{M} \mathrm{H}_{2} \mathrm{SO}_{4}$ are likely to arise from a combination of factors associated with the pretreatment of the gold electrode in concentrated nitric acid: (i) electrochemically induced preferential crystallographic orientation of the surface, (ii) chemically and electrochemically assisted incorporation of dissolved oxygen into the gold lattice, and (iii) other surface-related effects, arising from the potential limits and shape of the potential perturbation used in the pretreatment event. However, this particular variation of the earlier developed experimental technique ${ }^{14,15}$ described here is relatively simple and provides a new approach for measuring changes in solid electrode/solution interfacial tensions $\left(\Delta \gamma_{\mathrm{ML}}\right)$ and for the evaluation of potentials of zero charge for welldefined solid electrode surfaces (metals, metal oxides, etc.).

Acknowledgment. We are grateful to Lynn McCartney-Murphy for her typing and editing of this manuscript.

(55) Hamelin, A. J. Electroanal. Chem. 1986, 210, 303.

(56) Hamelin, A.; Stoicoviciu, L. J. Electroanal. Chem. 1987, 234, 93.

\title{
Fluorometric Titration of 4-Heptadecyl-7-hydroxycoumarin in Neutral Monolayers at the Air/Water Interface
}

\author{
Jordan G. Petrov ${ }^{\dagger}$ and Dietmar Möbius* \\ Max-Planck-Institut für biophysikalische Chemie, Postfach 2841, D-3400 Göttingen, FRG \\ Received July 29, 1988. In Final Form: December 19, 1988
}

\begin{abstract}
Fluorescence spectra of 4-heptadecyl-7-hydroxycoumarin in monolayers of methyl arachidate and eicosanol at the air/water interface were obtained, and the air/water $\mathrm{p} K$ values were estimated from fluorometric titration of the indicator. These values were compared with literature data for the same dye embedded in deposited monolayers, micelles, and other spread monolayers of different neutral substances.
\end{abstract}

\section{Introduction}

Fluorescent probes were often applied as interfacial $\mathrm{pH}$ indicators and detectors of interfacial polarity and electrostatic potentials of micelles, ${ }^{1-5}$ vesicles,,${ }^{1,6-8}$ model biomembranes, ${ }^{7,9}$ and monolayers deposited on solid substrates by means of the Langmuir-Blodgett technique. ${ }^{10-13}$ In some cases, $7,14-17$ fluorescence measurements were reported also at the air/water interface, thus providing a new

\footnotetext{
${ }^{+}$Fellow of the Alexander von Humboldt-Stiftung. Permanent address: Department of Physical Chemistry, University of Sofia, 1,
} Anton Ivanov Ave., 1126 Sofia, Bulgaria. possibility to characterize the structure and electrostatic properties of spread monolayers.

(1) Mukerjee, P.; Banerjee, K. J. Phys, Chem. 1964, 68, 3567.

(2) Montal, M.; Gitler, C. Bioenergetics 1973, 4, 363.

(3) Fernandez, M. S.; Fromherz, P. J. Phys. Chem. 1977, 81, 1755.

(4) Funasaki, N. J. Colloid Interface Sci. 1977, 60, 54.

(5) Drumond, C. J.; Grieser, F. Photochem. Photobiol. 1987, 45, 19.

(6) Haase, A. Ph.D. Dissertation, Justus Liebig University, Giessen, 1980.

(7) Teissiê, J.; Tocanne, F.; Pohl, W. G. Ber. Bunsen-Ges. Phys. Chem. $1978,82,875$.

(8) Lukac, S. J. Phys. Chem. 1983, 87, 5045.

(9) Fromherz, P.; Kotulla, R. Ber. Bunsen-Ges. Phys. Chem. 1984, 88, 1106 . 
In order to determine the interfacial potential $\Psi_{0}$, one needs the value of the intrinsic dissociation constant of the probe at the interface, $K_{\mathrm{i}}$ :

$$
\Psi_{0}=\frac{2.3 R T}{F}\left(\mathrm{p} K_{\mathrm{i}}-\mathrm{p} K\right)
$$

Here $R$ is the gas constant, $T$ temperature, $F$ the Faraday constant, and $\mathrm{p} K$ and $\mathrm{p} K_{\mathrm{i}}$ the values obtained at the charged surface and at a surface where $\Psi_{0}=0$, respectively.

The data available in the literature show that even for the same dye, the $\mathrm{p} K_{\mathrm{i}}$ values differ for different neutral matrixes. Obviously, $\mathrm{p} K_{\mathrm{i}}$ depends on the chemical nature of the chromophore environment (its polarity) and on the physical state and structure of the interface (its curvature, molecular mobility, etc.). In particular, it has been shown that neutral monolayers have different normal dipole moment components of their hydrophilic head groups. ${ }^{18}$ Therefore, it is of particular interest to compare the results for neutral monolayers at the air/water interface with those for deposited monolayers and micelles, obtained with the same fluorescent probe.

The present study deals with 4-heptadecyl-7-hydroxycoumarin (HHC) at the air/water interface. This is the most frequently used dye in the other types of organized systems, and it is spectroscopically well characterized. The HHC molecules were embedded into methyl arachidate and eicosanol monolayers, and their fluorescence spectra were recorded at different subsolution $\mathrm{pH}$. From the titration curves the air/water values of $\mathrm{p} K_{\mathrm{i}}$ were determined. The interfacial dielectric constants $\epsilon_{\mathrm{i}}$ were evaluated (by means of the procedure used in ref 3) and compared with literature data for other neutral matrices.

\section{Experimental Section}

Materials. Water from a Milli-Q system and Merck inorganic substances of AR purity grade were used for the aqueous subsolutions. The $\mathrm{pH}$ was adjusted by means of $\mathrm{KH}_{2} \mathrm{PO}_{4}, \mathrm{Na}_{2} \mathrm{HPO}_{4}$, and $1 \mathrm{M} \mathrm{HCl}$ and $1 \mathrm{M} \mathrm{NaOH}$ at approximately constant ionic strength of $1 \times 10^{-2} \mathrm{M}$. The $\mathrm{pH}$ was determined prior to and after recording the spectra (samples of the subsolutions from the trough were taken), and the changes observed were not greater than 0.1 $\mathrm{pH}$ unit.

The 4-heptadecal-7-hydroxycoumarin $\left(\mathrm{mp} 92-93^{\circ} \mathrm{C}\right)$ used in this investigation was synthesized according to Sondermann..$^{19}$ The methyl arachidate (MA) was from Merck, for chromatographic purposes, and was used without further purification. The Merck eicosanol (EO) was additionally recrystallized to a melting point of $63.0-63.8^{\circ} \mathrm{C}$. The mixtures of HHC with these substances were prepared from their $1 \times 10^{-3} \mathrm{M}$ chloroform solutions.

Technique and Procedure. The experimental setup for recording fluorescence spectra from the air/water interface is shown schematically in Figure 1. The excitation part of the system consists of a HBO 100 mercury lamp, a $180-400-\mathrm{nm}$ monochromator (Bausch \& Lomb with 2700 grooves $/ \mathrm{mm}$ grating, bandwidth of $10 \mathrm{~nm}$ ), chopper (PTI, Mod. 03-OC-4000), and a quartz fiber bundle serving as an optical guide. By means of a similar optical guide, the fluorescence of the spread monolayer is picked up and transferred to another monochromator ( $B$ \& $M$ Spectronic, with 600 grooves/nm grating, 10-nm bandwidth)

(10) Fromherz, P. Biochim. Biophys. Acta 1973, 323, 326.

(11) Fromherz, P.; Masters, B. Biochim. Biophys. Acta 1974, 356, 270 501 . (1)

(12) Lovelock, B.; Grieser, F.; Healy, T. W. J. Phys. Chem, 1985, 89,

(13) Lovelock, B.; Grieser, F.; Healy, T. W. Langmuir 1986, $2,443$.

(14) Teissiê, J.; Tocanne, J. F; Baudras, A. FEBS Lett. 1976, 70, 123

(15) Heckl, W. M.; Lösche, M.; Cadenhead, D. A.; Möhwald, H. Eur. Biophys. J. 1986, 14, 11.

(16) Grieser, F.; Thistlethwaite, P.; Traindos, P. J. Am. Chem. Soc. $1986,108,3844$.

(17) Sancaille, P.; Prates, M.; Tocanne, J. F.; Teissiê, J. Biochim. Biophys. Acta 1988, 939, 289.

(18) Vogel, V.; Möbius, D. J. Colloid Interface Sci. 1988, 126, 408.

(19) Möbius, D.; Bücher, H.; Kuhn, H.; Sondermann, J. Ber. BunsenGes. Phys. Chem. 1969, 73, 835.

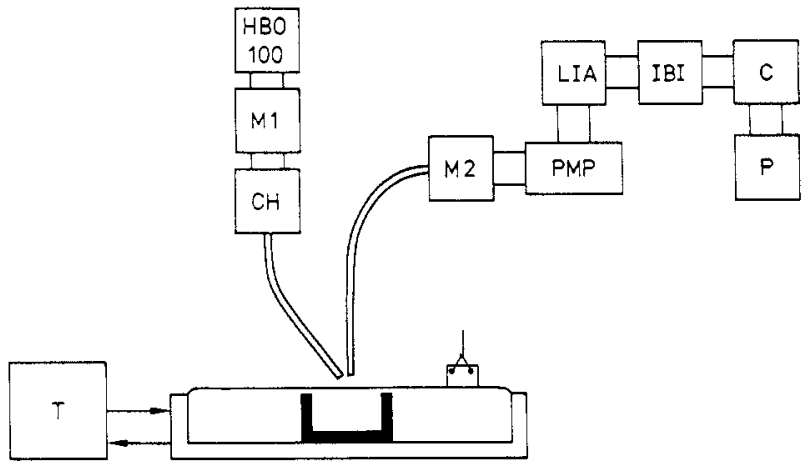

Figure 1. Schematic representation of the experimental setup. HBO-100, exciting mercury lamp; M1, M2, exciting and registering monochromators; $\mathrm{CH}$, chopper; PMP, photomultiplier; LIA, lock-in amplifier; IBI-IEC, bus interface; C, computer; $\mathrm{P}$, plotter.

provided with a photomultiplier (EMI $9669 \mathrm{QB}$ ) in a cooled housing (TE-104 RF). The signal from the photomultiplier is amplified by a Synchro-Het lock-in amplifier (PAR, Mod. 186), put via digitizer and IEC bus interface into a computer, and plotted as a function of wavelength.

The light reflected and scattered from the pure water surface and from the bottom of the Langmuir-Adam trough gives a considerable contribution to the signal in this measurement. For this reason a light trap of black neutral glass in the form of a rectangular cuvette was mounted on the bottom of the trough, immediately below the ends of the exciting and measuring optical guides. The ends of these guides have been adjusted in the vertical direction as well as with respect to each other until the scattered and reflected light entering the registering part of the system has been minimized. In our arrangement the optimum position corresponded to a distance of the ends from the water surface of about $3 \mathrm{~mm}$ and an angle between the light guides of about $55^{\circ}$.

Monolayers containing $\mathrm{HHC}$ were spread onto the aqueous subsolution in a rectangular Langmuir-Adam trough that was connected to a thermostat maintaining constant temperature (20.5 $\pm 0.1^{\circ} \mathrm{C}$ in these experiments). Two minutes after spreading, necessary for evaporation of the spreading solvent, the monolayer was slowly compressed to $30 \mathrm{mN} / \mathrm{m}$. This surface pressure (measured by the Wilhelmy plate method with a filter paper) was kept constant during the recording of the spectra by means of a servo mechanism. The values of the initial and final monolayer area at $30 \mathrm{mN} / \mathrm{m}$ served as a control for changes of the monolayer density during the measurement. In all experiments these changes were less than $0.5 \%$.

Under these conditions a "blank" spectrum from the pure air/water interface was recorded. (The blank spectrum showed a broad band between 415 and $435 \mathrm{~nm}$ (probably Raman scattering of the water) and continually decreasing intensity up to $580 \mathrm{~nm}$ ). This spectrum was taken as a reference and subtracted from the spectrum of the monolayer containing the fluorescent probe. The resulting spectra have been recorded between 400 and $600 \mathrm{~nm}$. Since the excitation was performed at $366 \mathrm{~nm}$ ( $\lambda_{\max }$ of the ionized HHC), where the neutral form does not absorb at all, ${ }^{20}$ the spectra obtained at each $\mathrm{pH}$ are interpreted as being exclusively due to the anionic $\mathrm{HHC}$ form.

\section{Results}

In titrations of a fluorescent acid or base in a mixed monolayer, such mixtures should be used that ensure a proportionality between the fluorescence intensity $I$ and the dye molar fraction $X$. Figure 2 shows $I$ at $\lambda_{\max }$ of the ionized form of HHC for different mixtures with methyl arachidate (subsolution $\mathrm{pH}=12.0$ ). The experimental points up to $X_{\mathrm{HHC}}=5 \times 10^{-3}($ molar ratio $\varphi=1 / 200)$ are on a straight line going through the origin. A deviation is seen for $\varphi=1 / 100$, demonstrating that only $\varphi<1 / 200$ can be used for the purpose of this study. We chose $\varphi=$

(20) Chen, R. F. Anal. Lett. 1968, 1, 423. 


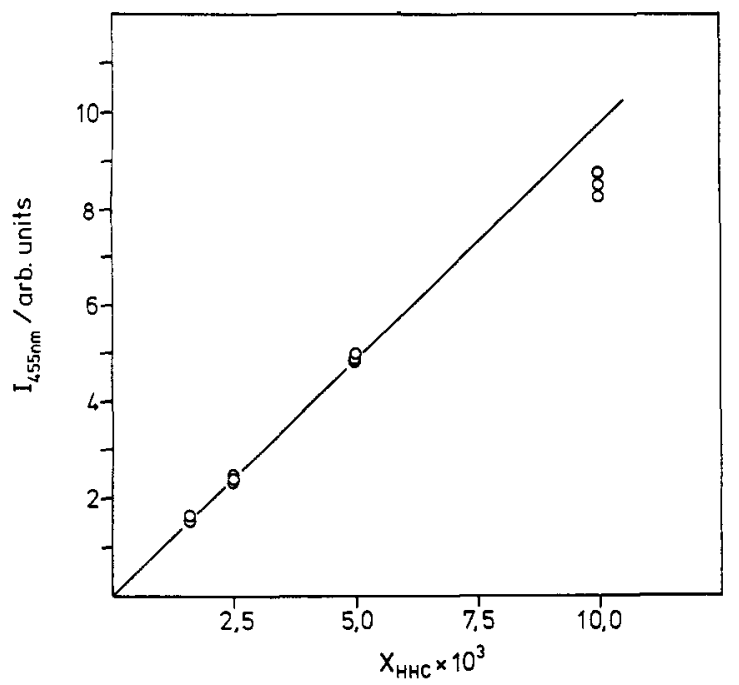

Figure 2. Fluorescence intensity of $\mathrm{HHC}$ at $455 \mathrm{~nm}$ in methyl arachidate monolayer versus the dye molar fraction. Subsolution $\mathrm{pH} 12.0$.

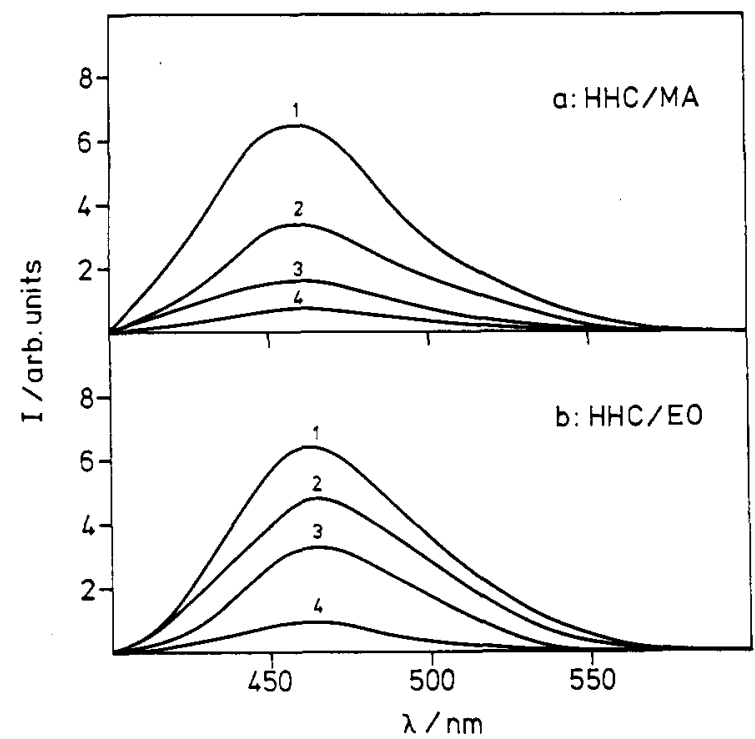

Figure 3. Fluorescence spectra of HHC in methyl arachidate (a) and eicosanol (b) monolayers. Molar ratio of the dye in both cases is $1 / 400$. (a) $1, \mathrm{pH} 11.2$ and $12.0 ; 2, \mathrm{pH} 8.3 ; 3, \mathrm{pH} 7.5 ; 4$, pH 6.9. (b) $1, \mathrm{pH} \mathrm{9.4,11.2,} \mathrm{and} 12.0 ; 2, \mathrm{pH} 8.5 ; 3, \mathrm{pH} 7.7 ; 4, \mathrm{pH}$ 6.9 .

1/400 for the HHC/MA and HHC/EO mixtures since this ratio was used by Fromherz and Masters ${ }^{11}$ in a titration of $\mathrm{HHC}$ in methyl stearate monolayers, deposited onto glass substrates covered with several monolayers of methyl stearate (see Discussion).

Figure 3 shows the fluorescence spectra of $\mathrm{HHC}$ in methyl arachidate and eicosanol monolayers at different $\mathrm{pH}$ values. Each spectrum is the average of three independent measurements, including spreading of a new monolayer. For this reason the noise of the signal (about one-half an arbitrary unit) is not plotted in the figure.

Following the variation of the fluorescence intensity $I$ at $\lambda_{\max }$ with the subsolution $\mathrm{pH}$, the corresponding titration curves, presented in Figure 4, were obtained. The values of the abscissa at their inflection points give $\mathrm{p} K_{\mathrm{i}}$ $=8.20$ for methyl arachidate and $p K_{i}=7.75$ for eicosanol matrices.

In order to see if any changes in time exist that could influence the titration curves, we have repeated the measurement of the spectrum of the same monolayer 15 and $30 \mathrm{~min}$ after the first measurement. All three spectra

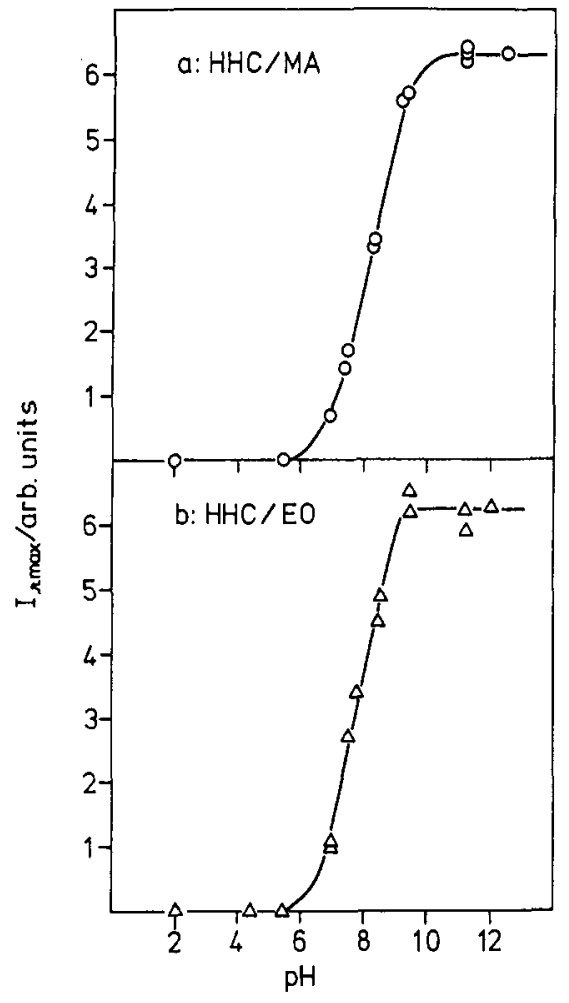

Figure 4. Fluorescence intensity at $\lambda_{\max }$ versus subsolution $\mathrm{pH}$. (a) $\mathrm{HHC} / \mathrm{MA}=1 / 400 ;$ (b) $\mathrm{HHC} / \mathrm{EO}=1 / 400$.

obtained in this way coincided.

On the basis of the proportionality between fluorescence intensity and surface density of the ionized HHC molecules, one can calculate the dissociation degree $\alpha$ of the fluorescent probe in the monolayers.

$$
\alpha=I / I_{\max }
$$

Applying the well-known equation for a monobasic acid

$$
\log \frac{\alpha}{1-\alpha}=\mathrm{pH}-\mathrm{p} K
$$

one can plot $\log (\alpha /(1-\alpha))$ vs $\mathrm{pH}$ to obtain $\mathrm{p} K$ from an interpolation at $\log (\alpha /(1-\alpha))=0$. Such plots, giving $\mathrm{p} K_{\mathrm{i}}$ values of 8.15 and 7.75 , are shown in Figure 5. However, the slopes of these plots are 0.78 and 0.80 for AME and EO, respectively. Slopes of about 0.80 can be obtained of all experimental points for deposited methyl stearate monolayers, ${ }^{11}$ and the neutral micelles of $n$-dodecyl $\beta$-Dmaltoside and $n$-dodecyl ethylenglycol monoether ${ }^{21}$ are represented in the same way. Obviously, similar deviations of the observed slope from 1 are not exceptions or experimental errors. This demonstrates that the $\mathrm{p} K$ values obtained are varying with $\mathrm{pH}$, a fact that needs further consideration and explanation. (As shown in ref 5, a precise determination of $\mathrm{pK}$ in a small $\mathrm{pH}$ interval around the $\mathrm{p} K$ value (about 1.5 units) confirms the interpolated $\mathrm{p} K$ values.)

An interesting effect was observed when the surface pressure, at which the spectrum was recorded, was reduced. In contrast to the expectation, Figure 6 shows an increase of the fluorescence intensity when $\pi$ and consequently the $\mathrm{HHC}$ surface density decrease. The spectra taken at 30 and $20 \mathrm{mN} / \mathrm{m}$ (solid condensed state) were identical, and the spectrum taken at $10 \mathrm{mN} / \mathrm{m}$ (liquid condensed state) showed an increased fluorescence intensity at $\lambda>430 \mathrm{~nm}$.

(21) Drummond, C. J.; Warr, G. G.; Grieser, F.; Ninham, B. W.; Evans, D. F. J. Phys. Chem. 1985, 89, 2103.

(22) Parsons, R. Croat. Chem. Acta 1976, 48, 597. 


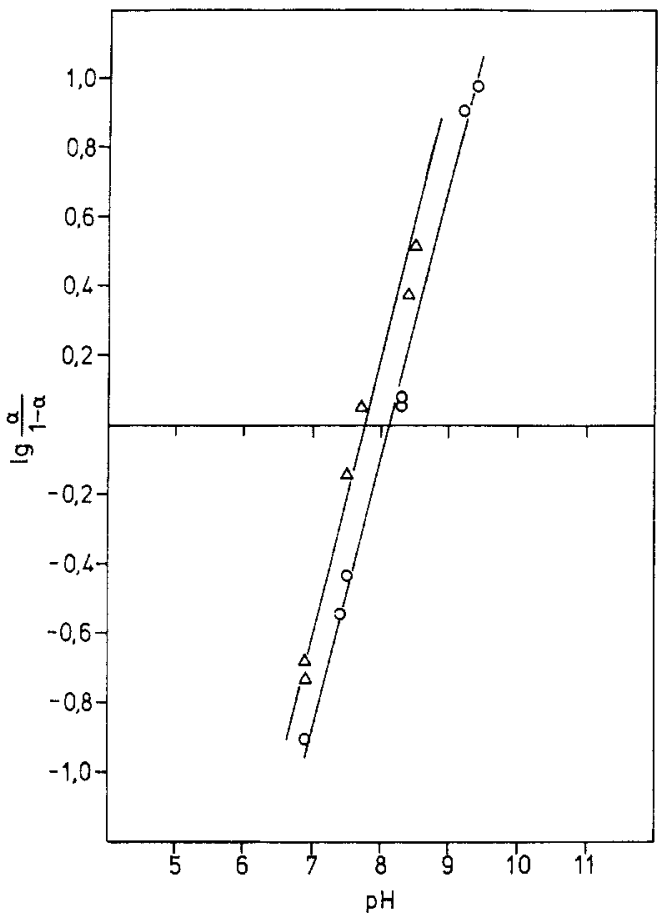

Figure 5. Linearization of the titration data (Figure 4) according to eq 3 .

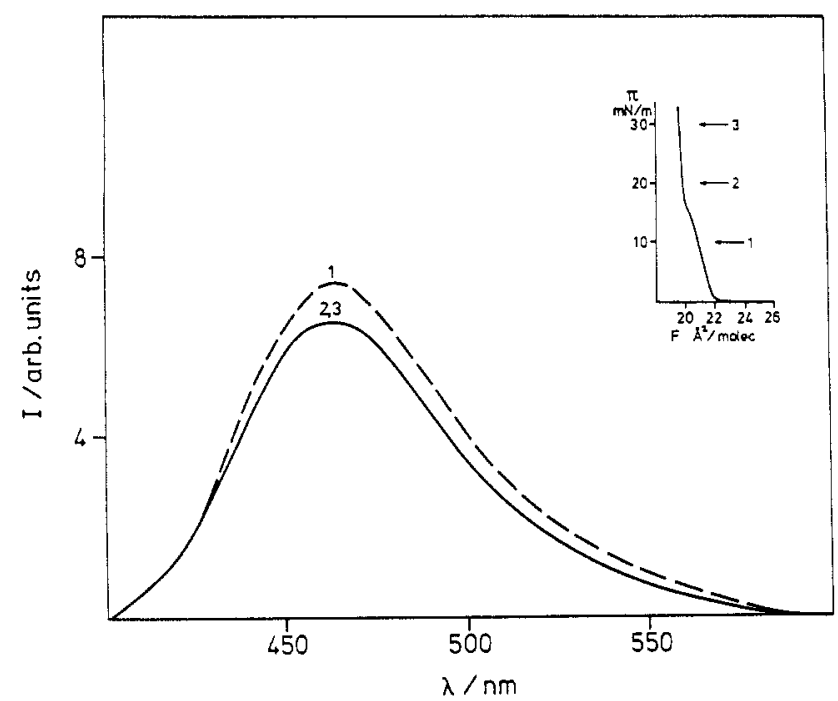

Figure 6. Effect of the constant surface pressure on the fluorescence spectra of $\mathrm{HHC}$ in eicosanol $(\varphi=1 / 400)$ at $\mathrm{pH} 12.0$. In the inset the $\pi / F$ isotherm of eicosanol is shown. (1) $\pi_{\text {const }}=$ $10 \mathrm{mN} / \mathrm{m} ;(2) \pi_{\text {const }}=20 \mathrm{mN} / \mathrm{m}$; (3) $\pi_{\text {const }}=30 \mathrm{mN} / \mathrm{m}$.

This fact demonstrates the sensitivity of the fluorescence spectra of $\mathrm{HHC}$ to changes of the physical state of the monolayer. With other fluorescent probes in phospholipid monolayers even stronger, phase transition effects have been observed. ${ }^{14,15}$

\section{Discussion}

The values of $\mathrm{p} K_{\mathrm{i}}$ obtained in this study are shown in Table I together with data for HHC and PHC (4-pentadecyl-7-hydroxycoumarin) in other neutral matrices. Fluorescence intensity $I$ or dye absorption $A$ at the respective $\lambda_{\max }$ were measured in different cases, and both titration parameters gave identical results. ${ }^{7,19}$ The table contains also some of the factors affecting the $\mathrm{p} K_{\mathrm{i}}$ determination ( $\varphi_{\mathrm{HHC}}$ surface pressure, aqueous solution composition, temperature). Their importance will be discussed separately in order to outline the correctness and comparability of the data quoted.
As Figure 2 shows, $\varphi_{\mathrm{HHC}}$ in $\mathrm{RCOOCH}_{3}$ monolayers has to be less than $1 / 200$ to obtain correct titration curves. An application of higher dye molar ratios leads to lower $I_{\lambda}$ values; i.e., the $I_{\lambda} / \mathrm{pH}$ dependence is shifted to higher $\mathrm{pH}$ and thus to higher (incorrect) $\mathrm{p} K_{\mathrm{i}}$ values. Probably for this reason Fromherz ${ }^{10}$ obtained $\mathrm{p} K_{\mathrm{i}}=9.5$ with a $1 / 50$ $\mathrm{HHC} /$ methyl palmitate mixture and a lower $\mathrm{p} K_{\mathrm{i}}=8.6$ with a $1 / 400 \mathrm{HHC} /$ methyl stearate ${ }^{11}$ mixture, both deposited on hydrophobized glass substrates.

Earlier investigations ${ }^{7,17}$ reported an increase of $\mathrm{p} K_{\mathrm{i}}$ at higher $\pi_{\text {const }}$ in spread monolayers of 1,2-dipalmitoyl-snglycerol-3-phosphorylcholine, egg lecithin, and phosphatidylethanolamine. In ref 7 it was proved that this change is not due to an increase of the dye surface density. The same effect follows from the result shown in Figure 6, although the reason could be different for zwitterionic and neutral substances. On the other hand, the influence of $\pi$ on the fluorescence intensity (and, respectively, on $\mathrm{p} K_{\mathrm{i}}$ ) depends on the location of the dye in the monolayer. As ref 14 demonstrated, all of the three possibilities of higher, lower, and constant $I_{\lambda}$ could be observed when $\pi$ increases, if different fluorescent probes are used. For this reason, special attention should be paid to $\pi_{\text {const }}$ when $\mathrm{p} K$ values in spread and deposited monolayers are determined and compared.

Another aspect of the influence of $\pi_{\text {const }}$ is related to monolayer stability. If it is not especially necessary to work at very high packing density, surface pressure that is lower than the equilibrium spreading pressure $\pi_{\mathrm{e}}$ should be chosen. This is the case with the eicosanol monolayer in this study $\left(\pi_{\mathrm{e}}=33 \mathrm{mN} / \mathrm{m} \text { at } 25^{\circ} \mathrm{C}\right)^{23}$ but not with the methyl palmitate ${ }^{10}\left(\pi_{\mathrm{e}}=14 \mathrm{mN} / \mathrm{m}\right.$ at $\left.20^{\circ} \mathrm{C}\right) .^{23}$ Therefore, the methyl palmitate monolayer is thermodynamically unstable and may collapse at the surface pressure of $25-45$ $\mathrm{mN} / \mathrm{m}$ applied in ref 10 .

When fluorescence spectra are determined, the temperature should be kept strictly constant because of the extreme sensitivity of the fluorescence efficiency to temperature variations ( $2 \%$ per degree for tryptophan and proteins, for instance). ${ }^{26}$ In fluorometric titrations this effect is coupled with the temperature dependence of $K$ (sometimes nonmonotonous), making the influence of temperature on $\mathrm{p} K$ unpredictable.

The data presented in Table I and other results not included there show that the composition of the aqueous solution does not play an important role in $\mathrm{p} K$ determination in neutral matrices. ${ }^{5,11}$ It could become a significant factor, however, if some specific interactions or salt effects influence the dissociation of $\mathrm{HHC}$ in the monolayer $\left(\mathrm{p} K_{\mathrm{i}}\right)$ or that of its soluble homologue in water $\left(\mathrm{p} K_{\mathrm{w}}\right)$. This is probably the case with the different $\mathrm{p} K_{\mathrm{i}}$ values of $\mathrm{HHC}$ in methyl palmitate monolayers deposited from $1 \times 10^{-2}$ $\mathrm{M} \mathrm{NaCl}$ and $1 \times 10^{-2} \mathrm{M} \mathrm{CaCl}_{2}$ subsolutions. ${ }^{10}$ The alternative explanation proposed in ref 10 , namely, incorporation of $\mathrm{Ca}^{2+}$ in the deposited structure, is not consistent with the chemical analyses of methyl stearate ${ }^{24}$ and methyl arachidate ${ }^{25}$ multilayers built up from $\mathrm{CdCl}_{2}$ subsolutions.

In order to reduce (or exclude) the above-mentioned effects on $\Delta \mathrm{p} K_{\mathrm{i}}=\mathrm{p} K_{\mathrm{i}}-\mathrm{p} K_{\mathrm{w}}$ and on $\epsilon_{\mathrm{i}}$, a parallel determination of $\mathrm{p} K_{\mathrm{i}}$ and $\mathrm{p} K_{\mathrm{w}}$ at the same temperature and

(23) Gaines, G. L., Jr. Insoluble Monolayers at Liquid-Gas Interfaces Wiley-Interscience: New York, 1966; pp 213, 241.

(24) Petrov, J. G.; Kuhn, H.; Möbius, D. J. Colloid Interface Sci. 1980 73,66 .

(25) Petrov, J. G.; Kuleff, I.; Platikanov, D. J. Colloid Interface Sci. $1982,88,29$.

(26) Chen, R. F. Analytical Biochemistry 1967, 20, 339. 


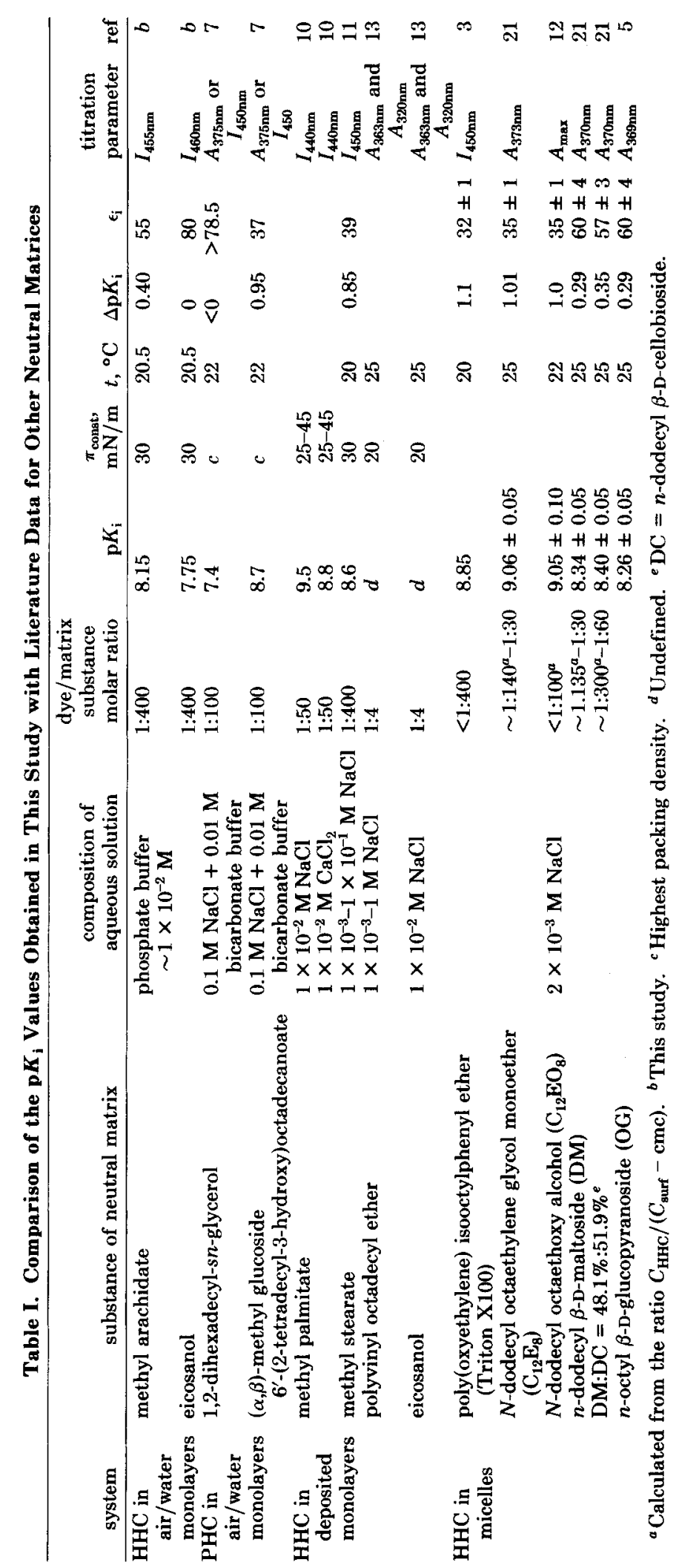

aqueous phase composition is desirable. The importance of this requirement is obvious by comparison of $\mathrm{p} K_{\mathrm{i}}$ and $\Delta \mathrm{p} K_{\mathrm{i}}$, respectively, $\epsilon_{\mathrm{i}}$ values from Table I, the latter being closer to each other for similar substances.

A particularly interesting result was obtained for the eicosanol monolayer in this study. The air/water $\mathrm{p} K_{\mathrm{i}}=$ 7.75 was found to be equal to the bulk $\mathrm{p} K_{\mathrm{w}}$ of the soluble 4-methyl-7-hydroxycoumarin. This may be interpreted as evidence for unchanged water structure at the air/water interface in the vicinity of the monolayer hydroxy groups. However by use of molecular models to look more closely at the actual arrangement of the HHC chromophores in the solid condensed eicosanol monolayer, it becomes clear that the reactive group of the dye lies underneath the eicosanol $\mathrm{OH}$ groups. If this is the reason for the absence of any difference between $\mathrm{p} K_{\mathrm{i}}$ and $\mathrm{p} K_{\mathrm{w}}$, found in this study, the above result means that $\epsilon_{i}$ changes steeply with distance from the monolayer hydroxyl groups, reaching its bulk value after 2-3 water layers.

Table I shows also that $\mathrm{p} K_{\mathrm{i}}<\mathrm{p} K_{\mathrm{w}}$ was reported for a spread monolayer of 1,2-dihexadecylglycerol. ${ }^{7}$ This means an interfacial dielectric constant $\epsilon_{i}$ is greater than $\epsilon$ of the bulk water, i.e., that the water structure around the monolayer hydroxyl groups can be more ordered ("icelike") than the bulk water structure. Such a conclusion correlates with the regular hexagonal lattice and the $\epsilon_{i}$ value near to that of ice, observed for intercalated water in clay structures. ${ }^{22}$ Unfortunately, the literature data for deposited $\mathrm{HHC}$ /EO monolayers, quoted in Table I, cannot be used to elucidate these interesting results in more details. The titration curves obtained in ref 13 demonstrate a complicated and as yet incomprehensible $\mathrm{p} K_{\mathrm{i}} / \mathrm{pH}$ dependence.

The titration of $\mathrm{HHC}$ in methyl arachidate monolayer at the air/water interface showed $\mathrm{p} K_{\mathrm{i}}=8.15$. This value is lower than the $\mathrm{p} K_{\mathrm{i}}=8.6$ for deposited methyl stearate monolayers, found under the same experimental conditions in ref 11 . An estimation of the interfacial dielectric constants (using the $\Delta \mathrm{p} K / \epsilon$ plot from ref 11 ) gives $\epsilon_{\mathrm{i}}=55$ for the spread and $\epsilon_{i}=39$ for the deposited monolayer. This difference is opposite to the expected one if the influence of the outer phase is considered. Since both the solid/ liquid (ref 11) and gas/liquid (this study) interfaces consist of closely packed ester groups, a more regular water structuring, higher $\epsilon_{\mathrm{i}}$, is expected near the solid substrate. We cannot give a plausible nonspeculative explanation of this difference now; a direct comparison with deposited methyl arachidate monolayers is still in progress.

The interfacial dielectric constant evaluated from the $\mathrm{p} K_{\mathrm{i}}$ of $\mathrm{PHC}$ in a spread monolayer of the complicated $(\alpha, \beta)$-methyl glucoside ester ${ }^{7}$ is also lower than our $\epsilon_{\mathrm{i}}$ value and very close to that for deposited methyl stearate. However, the different chemical nature of the monolayer head groups and a possible different position and orientation of the dye chromophores does not allow any conclusion to be drawn from this comparison.

The same reasons and probably the interfacial curvature cause the difference between our $\epsilon_{i}$ values and those obtained at the surfaces of micelles of neutral surfactants. The lower density of the hydrophilic head groups in micelles can cause on one side a larger amount of water penetration but on the other side lower the order of the hydration water in contact with the hydrophobic part of the surfactant molecules. The best comparison between monolayers and micelles can be made with the Triton $\mathrm{X}$ 100 micelles $^{3}$ since the fluorometric titration of $\mathrm{HHC}$ in this study is performed at the same dye molar ratio and temperature. The value of $\epsilon_{i}=32$ found for this system 
is very close to $\epsilon_{\mathrm{i}}$ for micelles of other polyoxyethylene derivatives but distinguishably lower than our methyl arachidate value. On the other side, the interfacial dielectric constants of the hydrophilic micelles ${ }^{21}$ form another group of similar $\epsilon_{\mathrm{i}}$ values being also about 20 units lower than $\epsilon_{i}$ for eicosanol monolayer.

The $\mathrm{p} K_{\mathrm{i}}$ values given in Table I cover a range of about $1.7 \mathrm{p} K$ units ( 1.3 units only for spread neutral monolayers), corresponding to a difference of $100 \mathrm{mV}(77 \mathrm{mV}$, respectively), if the lowest and the highest values are taken as $\mathrm{p} K_{\mathrm{i}}$ of the standard uncharged interface in eq 1 . This fact puts in question the applicability of a universial $\mathrm{p} K_{\mathrm{i}}$, often used when the interfacial potential is calculated for micellar systems. On the other hand, the closeness of the values of $\mathrm{p} K_{\mathrm{i}}$, found in this study for neutral amphiphiles differing only in their polar head groups, emphasizes the necessity of new detailed investigations with other simple neutral matrices under comparable and well-defined conditions. The monolayer spectroscopy at the air/water interface is a useful tool for such studies.

Acknowledgment. J.G.P. thanks the Alexander von Humboldt-Stiftung for the award of a research fellowship that made possible this investigation.

\title{
Compression of Adsorbed Monolayers at Oil/Water and Air/Water Interfaces Using a Reversed Funnel Method
}

\author{
J. Van hunsel, ${ }^{\dagger}$ D. Vollhardt,$^{\ddagger}$ and P. Joos*, ${ }^{*}$ \\ University of Antwerp, U.I.A., Departments of Chemistry and Biochemistry, Universiteitsplein \\ 1, B-2610 Wilrijk, Belgium, and Akademie der Wissenschaften der D.D.R., Zentralinstitut für \\ Organische Chemie, Bereich Grenzflächenaktive Stoffe, 5 Rudower Chaussee, \\ 1199 Berlin-Adlershof, D.D.R.
}

Received July 1, 1988. In Final Form: October 7, 1988

\begin{abstract}
After the establishment of equilibrium, adsorbed monolayers at the air/water and the oil/water interface are compressed, and the system relaxes to its equilibrium. In these stress-relaxation experiments, relaxation to equilibrium is monitored through the interfacial tension. At the air/water interface, the surface is compressed either in a Langmuir trough or by raising the level of the interface in a reversed funnel. Agreement between both experiments is excellent. This reversed funnel method is also used for compression of monolayers adsorbd at the oil/water interface. The results can be explained by a diffusion-controlled desorption process. The reversed funnel method is put forward as a new one for studying desorption kinetics at the oil/water interface.
\end{abstract}

\section{Introduction}

In a previous paper ${ }^{1}$ a new method was presented to study the relaxation of an adsorbed monolayer at the oil/water interface after a sudden stress in a time scale between about 5 and $1000 \mathrm{~s}$. This method consists of raising the equilibrated interface in a funnel rather quickly. In this way the adsorbed monolayer is expanded, and it will relax to its equilibrium situation again. As mentioned in our paper, this funnel method only works for expansion. If the interface in the funnel is lowered, one would expect the adsorbed monolayer to be compressed. However, a film of the aqueous solution adheres to the funnel wall, and because of this the monolayer is still expanded. Reestablishment of equilibrium is much slower now because the film surface has to be provided for with surface-active material from a bulk solution of limited surface area. Siliconizing the funnel wall or using a Teflon funnel does not give any improvement. On the contrary, due to irregular wetting, the results are very scattered.

The purpose of this paper is to present a simple method to study the relaxation of a suddenly compressed adsorbed monolayer at the oil/water interface in the same time scale. To check the validity of this method, experiments are first performed at the air/water interface, and these results are then compared with the results of the well-established

\footnotetext{
${ }^{\dagger}$ University of Antwerp.

: Akademie der Wissenschaften der D.D.R.
}

stress-relaxation method in a Langmuir trough. ${ }^{2,3}$ Also, the expansion results of the funnel method are taken into consideration.

There is ample evidence now that the adsorption properties of surfactants, particularly the adsorption and desorption kinetics, are likely to be affected by the presence of highly surface-active impurities. ${ }^{4}$ In this paper we show that a diffusion-controlled mechanism is found to hold for both a commercial nonionic surfactant and a highly purified anionic surfactant, fulfilling the requirements of surface chemical purity. ${ }^{5}$

\section{Experimental Section}

Compression of the adsorbed monolayer is performed by raising the interface between two equilibrated liquid phases in a reversed funnel, as sketched in Figure 1. We use an ordinary glass funnel (F), from which the top was cut off. This funnel is placed reversely in a vessel (V) in such a way as to leave enough space between its lower rim and the bottom of the vessel. This can be done by placing a Teflon bar (TB) in the vessel, on which the reversed funnel can be rested (Figure 2).

The interface is allowed to equilibrate at a level $\mathrm{S}_{0}$ (interfacial area $\Omega_{0}$ ). The equilibration is followed by monitoring the in-

(1) Van hunsel, J.; Joos, P. Colloids Surf. 1987, 25, 251.

(2) Balbaert, I.; Joos, P. Colloids Surf. 1987, 23, 259.

(3) Joos, P.; Bleys, G. Colloid Polym. Sci. 1983, 261, 1038

(4) Vollhardt, D.; Czichocki, G. Colloids Surf. 1984, 11, 209

(5) Miller, R.; Lunkenheimer, K. Colloid Polym. Sci. 1986, 264, 273. 